\title{
Suttonella ornithocola sp. nov., from birds of the tit families, and emended description of the genus Suttonella
}

Correspondence

Geoffrey Foster

Geoffrey.Foster@sac.co.uk

\author{
Geoffrey Foster, ${ }^{1}$ Henry Malnick, ${ }^{2}$ Paul A. Lawson, ${ }^{3}$ James Kirkwood, ${ }^{4}$ \\ Shaheed K. MacGregor ${ }^{4}$ and Matthew D. Collins ${ }^{5}$ \\ 'SAC Veterinary Services, Drummondhill, Stratherrick Road, Inverness IV2 4JZ, UK \\ ${ }^{2}$ Laboratory of Healthcare Associated Infection, Centre for Infections, Health Protection \\ Agency, London NW9 5HT, UK \\ ${ }^{3}$ Department of Botany and Microbiology, University of Oklahoma, Norman, OK 73019-0245, \\ USA \\ ${ }^{4}$ Institute of Zoology, Regent's Park, London NW1 4RY, UK \\ ${ }^{5}$ School of Food Biosciences, University of Reading, Reading RG6 6AP, UK
}

\begin{abstract}
Phenotypic and phylogenetic studies were performed on three strains of Gram-negative, rod-shaped organisms recovered from dead birds of the tit families (blue tit, coal tit and long-tailed tit). Morphological, cultural and biochemical studies indicated that the organisms were related to the family Cardiobacteriaceae in the gamma-subclass of the Proteobacteria. Comparative $16 \mathrm{~S}$ rRNA gene sequencing studies confirmed these findings and demonstrated that the bacterium represents a hitherto unknown subline within this family. The closest phylogenetic relative of the strains isolated from the birds was found to be Suttonella indologenes, although a sequence divergence of approximately $5 \%$ demonstrated that the unknown bacterium represented a novel species. On the basis of the results of the phylogenetic analysis and phenotypic criteria, it is proposed that the bacteria recovered from the diseased birds represent a novel species, Suttonella ornithocola sp. nov., with strain B6/99/2 ${ }^{\top}$ (= CCUG $49457^{\top}=$ NCTC $\left.13337^{\top}\right)$ as the type strain.
\end{abstract}

In 1990, Dewhirst et al. (1990) described the Cardiobacteriaceae, a new family within the gamma-subclass of the Proteobacteria, to include the genus Cardiobacterium and the newly defined genera Suttonella and Dichelobacter. The family Cardiobacteriaceae embraces fastidious Gramnegative bacilli associated with several diseases of man and other animals. The type species of the genus Cardiobacterium, Cardiobacterium hominis, is an occasional resident of the human respiratory tract and has been associated with bacteraemia and endocarditis (Wormser \& Bottone, 1983; Kiwan et al., 1989). The only other member of the genus with a validly published name, Cardiobacterium valvarum, originated from a case of human endocarditis (Han et al., 2004). The genera Dichelobacter and Suttonella include organisms previously classified as Bacteroides nodosus and Kingella indologenes, respectively (Dewhirst et al., 1990). Dichelobacter nodosus is the causative agent of footrot in sheep, goats and cattle (Skerman, 1989) and Suttonella indologenes has been recovered from human eye infections and from cases of endocarditis (Jenny et al., 1987; Sutton

The GenBank/EMBL/DDBJ accession number for the 16S rRNA gene sequence of Suttonella ornithocola sp. nov. B6/99/2 ${ }^{\top}$ is AJ717394. et al., 1972; van Bijsterveld, 1970). During the late winter of 1995/spring of 1996, a number of mass mortalities of predominantly male blue tits (Parus caeruleus), but also other related species, occurred in the UK (Kirkwood et al., 2005). In the course of bacteriological investigations following post-mortem examinations of some of these birds, fastidious Gram-negative, rod-shaped organisms were recovered from the congested lungs of the majority of birds examined. No other significant organisms were recovered from the birds and it is suspected that these Gram-negative, rod-shaped organisms may have been a factor in the deaths of the birds (Kirkwood et al., 2005).

Three strains collected from a blue tit, a coal tit (Parus acer) and a long-tailed tit (Aegthalos candatus) were selected for further detailed characterization. In this paper, we describe the cultural and biochemical characteristics of these bacteria and the results of a polyphasic taxonomic investigation.

The strains were isolated on Columbia blood agar base (Oxoid) supplemented with $5 \%$ citrated sheep blood (CSBA). Plates were incubated at $37^{\circ} \mathrm{C}$ in an aerobic atmosphere with $5 \%$ added $\mathrm{CO}_{2}$. $\beta$-Haemolytic colonies which attained a diameter of $2-3 \mathrm{~mm}$ after $48 \mathrm{~h}$ were 
recovered from the primary isolation plates. Three isolates were selected, transferred to fresh CSBA plates for maintenance and subjected to a range of characterization tests (Barrow \& Feltham, 1993). The ability to grow at $25^{\circ} \mathrm{C}$, $42^{\circ} \mathrm{C}$ and in air without added $\mathrm{CO}_{2}$ was tested on CSBA. Anaerobic growth was tested on pre-reduced CSBA in an anaerobic chamber. Growth was also checked on unsupplemented nutrient agar (Oxoid). Acid production from carbohydrates was assessed using phenol red broth sugars and peptone water sugars. Triple-sugar iron agar (TSI) was used to test for hydrogen sulphide production. Bile tolerance was tested on ditch plates with $40 \%$ bile agar. Alkaline phosphatase activity was determined using Rosco tablets (Bioconnections). Sensitivity to penicillin $\left(1.5 \mathrm{U} \mathrm{ml}^{-1}\right.$; Oxoid) was tested by disc diffusion.

Isolates were characterized phylogenetically using $16 \mathrm{~S}$ rRNA gene sequencing. $16 \mathrm{~S}$ rRNA genes were amplified by PCR using universal primers pA (sequence 5'-AGAGTTTGATCCTGGCTCAG-3', 8-28 Escherichia coli numbering) and $\mathrm{pH}$ (sequence $5^{\prime}$-AAGGAGGTGATCCAGCCGCA-3', 1542-1522) as described by Hutson et al. (1993) and sequenced directly using a Taq dye-deoxy terminator cycle sequencing kit (Applied Biosystems) and an automatic DNA sequencer (model 373A; Applied Biosystems). The closest known relatives of the bird isolates were identified by performing database searches using the FASTA program. These sequences, and those of other known related strains, were retrieved from GenBank and aligned with the newly determined sequences using the SEQtools program (Rasmussen, 2002). The resulting multiple sequence alignment was corrected manually using the GENEDOC program. A phylogenetic tree was constructed according to the neighbour-joining method with the SEQtools and TREEVIEW programs. The stability of the groupings was estimated by bootstrap analysis (1000 replications) using the same programs.

Three strains of a fermentative Gram-negative, rod-shaped bacillus were isolated from the congested lungs of three wild birds which had been examined following a mass mortality event. The organisms were catalase-positive, oxidasepositive and non-motile. When grown on CSBA at $37^{\circ} \mathrm{C}$ in a capnophilic atmosphere, colonies of the three isolates were circular, entire, low convex, shiny, opaque, grey, butyrous, attained a diameter of $2-3 \mathrm{~mm}$ after $48 \mathrm{~h}$ and were surrounded by a zone of $\beta$-haemolysis. Growth was poorer in air without added $\mathrm{CO}_{2}$ and in anaerobic conditions. Growth occurred on unsupplemented nutrient agar, at 25 and $42{ }^{\circ} \mathrm{C}$ and in the presence of $6 \% \mathrm{NaCl}$ and $40 \%$ bile, but not on MacConkey agar without salt. Casein was degraded and two strains hydrolysed Tween 20 and 80. Activity for alkaline phosphatase was positive, but negative for DNase and ONPG. Urease and indole were not produced and neither nitrates nor nitrites were reduced. $\mathrm{H}_{2} \mathrm{~S}$ production was negative in TSI. Tests for arginine dihydrolase and for lysine and ornithine decarboxylases were negative. Acid was produced from fructose, glucose, mannose, sucrose and trehalose, but not from galactose, inositol, lactose, maltose, mannitol, raffinose, salicin, sorbitol or xylose. The three isolates were sensitive to penicillin $\left(1.5 \mathrm{U} \mathrm{ml}^{-1}\right)$ by disc diffusion.

To investigate the phylogenetic position of the three bird isolates, their $16 \mathrm{~S}$ rRNA gene sequences were examined. The almost-complete gene sequences of the three strains were determined and pair-wise comparisons showed that the three isolates were highly related to each other, exhibiting 99.9-100\% sequence similarity (based on a comparison of approximately 1400 bases). The $16 \mathrm{~S}$ rRNA gene sequence of one of the strains, B6/99/2 ${ }^{\mathrm{T}}$, was used to search GenBank/ EMBL. The highest sequence similarities were found with species of the family Cardiobacteriaceae (data not shown). A tree constructed using the neighbour-joining method showing the phylogenetic position of strain $\mathrm{B} 6 / 99 / 2^{\mathrm{T}}$ in relation to members of the Cardiobacteriaceae and some other related organisms is presented in Fig. 1. The treeing program demonstrated that strain $\mathrm{B} 6 / 99 / 2^{\mathrm{T}}$ represents a hitherto unknown subline that clusters with $S$. indologenes.

In the present study, we have comprehensively characterized three strains of a hitherto unknown bacterium recovered from a blue tit, a coal tit and a long-tailed tit following mass mortalities amongst these species in the UK. It is evident from the results of the phenotypic and phylogenetic studies that the bird isolates represent a novel species within the family Cardiobacteriaceae. Phylogenetically, the closest relative of the bird isolates is S. indologenes. Strain B6/99/2 ${ }^{\mathrm{T}}$ formed a robust cluster with this species, supported by a bootstrap resampling value of $93 \%$. Despite this significant association, a $16 \mathrm{~S}$ rRNA gene sequence divergence of $5 \cdot 3 \%$ (based on 1400 nucleotide bases) clearly demonstrates that the bird isolates represent a species distinct from $S$. indologenes. D. nodosus was more distantly related to strain B6/ $99 / 2^{\mathrm{T}}$ as shown by a $16 \mathrm{~S}$ rRNA sequence divergence of $9 \%$. Although there is no precise correlation between 16S rRNA gene sequence divergence and species delineation, it is generally recognized that divergence values of $3 \%$ or more are significant (Stackebrandt \& Goebel, 1994). Support for the affinity between the bird isolates and the genus Suttonella is also apparent from phenotypic criteria. However, the bird isolates can be differentiated from $S$. indologenes on the basis of tests for $\beta$-haemolysis, catalase activity, indole production and fermentation reactions with some sugars (see Table 1). Therefore, based on both phenotypic and molecular genetic evidence, we are of the opinion that the strains isolated from the wild birds represent a novel species of the genus Suttonella, for which the name Suttonella ornithocola is proposed. The assignment of this novel species to the genus Suttonella, however, necessitates a revision of the genus description (see below).

\section{Emended description of the genus Suttonella Dewhirst et al. 1990}

The description of the genus Suttonella is as described by Dewhirst et al. (1990) except that the genus may be 


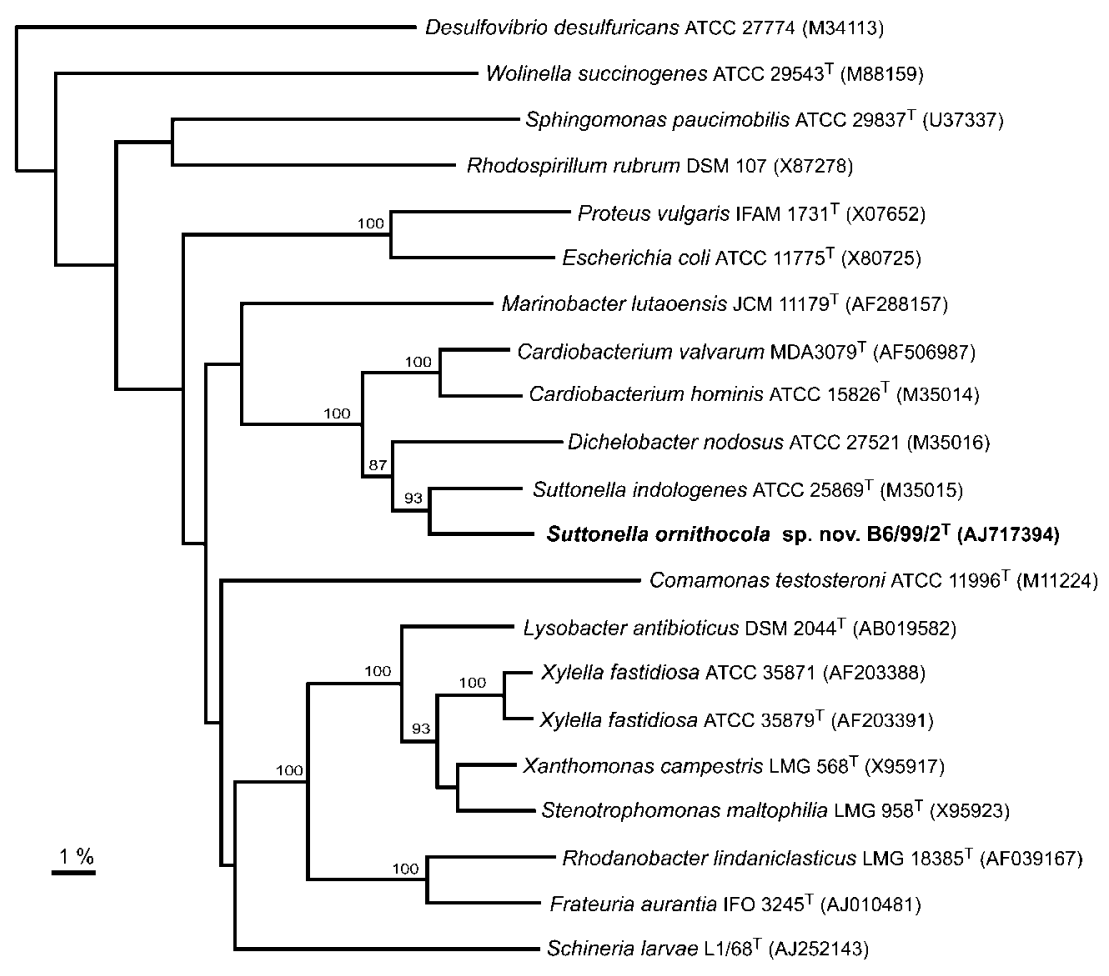

Fig. 1. Unrooted tree based on $16 \mathrm{~S}$ rRNA gene sequences showing the phylogenetic relationships of $S$. ornithocola sp. nov. with members of the Cardiobacteriaceae and related taxa. The tree was constructed using the neighbour-joining method and was based on a comparison of approximately 1327 nt. Bootstrap values, expressed as a percentage of 500 replications, are given at branch points. Bar, $1 \%$ sequence divergence. catalase-negative or -positive and indole may or may not be produced.

\section{Description of Suttonella ornithocola sp. nov.}

Suttonella ornithocola [or.ni'tho.co.la. Gr. n. ornis bird; L. suff. cola (from L. n. incola) dweller; N.L. n. ornithocola bird dweller].

The following description of morphological and physiological characteristics is based on the results of studies of three strains. Gram-negative, non-motile, non-encapsulated and non-spore-forming rods. Aerobic. Growth is enhanced by $\mathrm{CO}_{2}$. Colonies on CSBA incubated in a capnophilic

Table 1. Differential characteristics of $S$. ornithocola sp. nov. and $S$. indologenes

Data from this study and Dewhirst et al. (1990). +, Positive; D, different reactions with different strains; - , negative.

\begin{tabular}{|lcc|}
\hline & S. ornithocola S. indologenes \\
\hline Acid production from: & & + \\
$\quad$ Maltose & - & - \\
Trehalose & + & - \\
Catalase & + & - \\
Growth in presence of $6 \% \mathrm{NaCl}$ & + & - \\
$\beta$-Haemolysis & + & - \\
Hydrolysis of Tween 80 & $2 / 3$ & + \\
Indole production & - & $\mathrm{D}$ \\
Reduction of nitrite & - & \\
\hline
\end{tabular}

atmosphere at $37^{\circ} \mathrm{C}$ for $48 \mathrm{~h}$ are $2-3 \mathrm{~mm}$ in diameter, circular, entire, low convex, shiny, opaque, grey, butyrous and $\beta$-haemolytic. Growth occurs on unsupplemented nutrient agar and at 25 and $42{ }^{\circ} \mathrm{C}$, but is poorer in an anaerobic atmosphere. Growth occurs in $6 \% \mathrm{NaCl}$ and with $40 \%$ bile. Oxidase and catalase positive. Indole, urease and $\mathrm{H}_{2} \mathrm{~S}$ negative. Arginine dihydrolase, lysine decarboxylase and ornithine decarboxylase negative. Alkaline phosphatase positive. DNase and ONPG negative. Acid is produced from fructose, glucose, mannose, sucrose and trehalose. Acid is not produced from galactose, inositol, lactose, maltose, mannitol, raffinose, salicin, sorbitol or xylose. Nitrates and nitrites are not reduced. Growth does not occur on MacConkey agar without salt. Sensitive to penicillin $\left(1 \cdot 5 \mathrm{U} \mathrm{ml}^{-1}\right)$.

The type strain, B6/99/2 ${ }^{\mathrm{T}}$ (=CCUG $49457^{\mathrm{T}}=$ NCTC $13337^{\mathrm{T}}$ ), was isolated from the congested lungs of a coal tit.

\section{Acknowledgements}

SAC Veterinary Services receives financial support from the Scottish Executive Environment and Rural Affairs Department.

\section{References}

Barrow, G. I. \& Feltham, R. K. A. (1993). Cowan and Steel's Manual for the Identification of Medical Bacteria, 3rd edn. Cambridge: Cambridge University Press.

Dewhirst, F. E., Paster, B. J., La Fontaine, S. \& Rood, J. I. (1990). Transfer of Kingella indologenes (Snell and Lapage 1976) to the genus Suttonella gen. nov. as Suttonella indologenes comb. nov., transfer of Bacteroides nodosus (Beveridge 1941) to the genus Dichelobacter 
gen. nov. as Dichelobacter nodosus comb. nov.; and assignment of the genera Cardiobacterium, Dichelobacter, and Suttonella to Cardiobacteriaceae fam. nov. in the gamma division of Proteobacteria on the basis of $16 \mathrm{~S}$ rRNA sequence comparisons. Int J Syst Bacteriol 40, 426-433.

Han, X. Y., Meltzer, M. C., Woods, J. T. \& Fainstein, V. (2004). Endocarditis with ruptured cerebral aneurysm caused by Cardiobacterium valvarum sp. nov. J Clin Microbiol 42, 1590-1595.

Hutson, R. A., Thompson, D. E. \& Collins, M. D. (1993). Genetic interrelationships of saccharolytic Clostridium botulinum types B, E and $\mathrm{F}$ and related clostridia as revealed by small-subunit rRNA gene sequences. FEMS Microbiol Lett 108, 103-110.

Jenny, D. B., Letendre, P. W. \& Iverson, G. (1987). Endocarditis caused by Kingella indologenes. Rev Infect Dis 9, 787-789.

Kirkwood, J. K., MacGregor, S. K., Malnick, H. \& Foster, G. (2005). Unusual mortality incidents in tit species (Family Paridae) associated with hitherto unknown bacterium, Suttonella ornithocola. Vet Rec (in press).
Kiwan, Y., Shuhaiber, H. \& Chungh, T. (1989). Cardiobacterium hominis endocarditis. J Cardiovasc Surg (Torino) 30, 281-283.

Rasmussen, S. W. (2002). SEQtools, a software package for analysis of nucleotide and protein sequences. http://www.seqtools.dk

Skerman, T. M. (1989). Isolation and identification of Bacteroides nodosus. In Footrot and Foot Abscess of Ruminants, pp. 85-104. Edited by J. R. Egerton, W. K. Yong \& G. G. Riffkin. Boca Raton: CRC Press.

Stackebrandt, E. \& Goebel, B. M. (1994). Taxonomic note: a place for DNA-DNA reassociation and $16 \mathrm{~S}$ rRNA sequence analysis in the present species definition in bacteriology. Int J Syst Bacteriol 44, 846-849.

Sutton, R. G., O'Keeffe, M. F., Bundock, M. A., Jeboult, J. \& Tester, M. P. (1972). Isolation of a new Moraxella from a corneal abscess. $J$ Med Microbiol 5, 148-150.

van Bijsterveld, O. P. (1970). New Moraxella strain isolated from angular conjunctivitis. Appl Microbiol 20, 405-408.

Wormser, G. P. \& Bottone, E. J. (1983). Cardiobacterium hominis: review of microbiologic and clinical features. Rev Infect Dis 5, 680-691. 